\title{
Reinforcement delay and reinforcement rate as determinants of schedule preference'
}

\author{
Colin G. MeDiarmid, STANFORD UNIVERSITY \\ Mark E. Rilling, INDIANA UNIVERSITY
}

\begin{abstract}
Abstraet
Pigeons' preferences between two schedules of reinforcement were determined by a choice method. In each schedule-pair compared, one had a higher overall rate of reinforcement, but the other had a shorter delay before the first reinforcement. Delay before the first reinforcement was a strong determinant of schedule preference, but short delay could be offset by a large difference in rate of reinforcement.

\section{Problem}

Despite considerable investigation of the relation between performance and the scheduling of positive reinforcements, relatively few researches have investigated the "value" to S of particular schedules. In this context, value will be indexed by preferential choice between two stimuli, each associated with a reinforcement schedule. Given any set of schedules, how may we predict preference among them? The answer seems clear regarding fixed-criterion schedules varying within the same criterial dimension; e.g., shorter fixed ratios, intervals, or DRLs are undoubtedly preferred to longer fixed ratios, intervals, or DRLs, respectively. Within limits of discriminability, that schedule with the higher time-rate of reinforcement will be preferred. This principle also would probably predict accurately for choice between schedules specified by different criteria (e.g., fixed ratio versus fixed interval).

The question posed here is whether this "rate of reinforcement" principle is sufficient to generate the preference ordering Ss exhibit when the schedules compared are themselves variable, (e.g., two VI's, two VR's, a VI versus a VR). On VI's, for example, the variance (or range) as well as the mean of the intervals between reinforcements probably influences the choice. This is indeed true in the limit, since when the timerates of reinforcement are equated, a VI schedule is preferred over an FI schedule (Herrnstein, 1964b). Thus in addition to the overall rate of reinforcement, the time from the choice response to the first reinforcement may be an important determinant of preference.

An experiment by Autor (1960), carried out with an arrangement comparable to that described below, investigated pairs of VI schedules generated from an arithmetic progression. His pigeons preferred that member of each pair having the higher overall rate of reinforcement. However, among such VI schedules, overall rate of reinforcement and mean time to the first reinforcement covary. By using a fixed sequence of intervals, the present study isolates the time to the first reinforcement from the average rate of reinforce- ment on the schedule. In each of the three schedule-pairs compared, the HR schedule had a higher average rate of reinforcement, but the alternative, SD schedule, had a shorter delay before the first reinforcement.

Method

The Ss were three male White $\mathrm{C}$ arneaux pigeons maintained at $80 \%$ ad $1 \mathrm{ib}$ weight. The apparatus was a standard three-key pigeon box with associated control and recording equipment. Ss were first trained to respond on the center-key when it was illuminated, but not when it was dark. Each dav Ss received a series of alternating free- and forced-choice trials (16 trials of each for schedule pairs A and B; 20 of each for pair C). The free and forced trials were separated by 23 sec. time-outs, during which the keys were dark, and responding, which seldom occurred, had no effect. On free-choice trials, the two side keys were lighted, e.g., one red, one green, with the position of the colors varied in a Gellerman series. A single peck on one of these side keys removed the colors from the side-keys and produced the appropriate color and associated schedule of food reinforcement on the center key for a fixed time $(120 \mathrm{sec}$. for pairs $A$ and B, 42 sec. for pair C). For example, choice of the red side-key might produce a yellow center-key associated with the HR schedule; choice of the green side-key, a blue center-key with the SD schedule. To equate exposure to the two alternatives, following each free-choice trial, a forced trial was given to the unchosen colored side-key and its consequent center-key color and schedule.

The center-key schedules compared are shown in Table 1. The schedules were programmed as sequences of short "fixed-intervals," each of which preceded the availability of reinforcement, or the end of the trial. The times, measured from the onset of the corresponding center-key color, at which reinforcement was set up to be delivered for the next center-key peck, are given in rows 2, 5, and 6 of Table 1. Because of the type of performance generated by these schedules, almost all reinforcements were claimed within a second of their setup time. As Table 1 shows, the SD member of each schedule-pair involved a short delay of $6 \mathrm{sec}$. before the first reinforcement, whereas the HR member involved a higher overall rate of reinforcement (listed in rows 3 and 7). Going from pair A through B to C, the $\mathrm{SD}$ schedule becomes less favorable relative to the HR member of the pair.

The criterion for preference was 15 or 16 consistent choices in 16 free-choice trials. To assure reliabiltiy, the first $S$ run on each pair was reversed after meeting this initial criterion; for example, if the red side-key initially led to yellow-schedule SD on the center key, after reversal the green side-key produced this center-key combination whereas the red side-key produced the alternate combination. In all cases, S's side-key choices did reverse with this reversal in conditions. Other Ss subsequently exposed to the schedulepairs were run only to the initial criterion against their previously established color preference. Schedule-pair A was investigated with S 12, pair B with Ss 12,48 and 55, and pair C with Ss 12 and 48.

\section{Results}

In all cases, the Ss were consistent among themselves regarding their schedule preferences. As indicated in Table 1, the SD schedule was preferred in pairs $A$ and $\mathrm{B}$, the HR schedule in pair $\mathrm{C}$. This held true for reversal as well as original learning. For the first two pairs, the difference in time to the first reinforcement was sufficient to offset the difference in overall rate of 
Table 1. Schedule Pairs Used: Specifications and Birds' Preferences (Entries in rows $1,2,5$, and 6 are in sec.)

\begin{tabular}{lrrr}
\multicolumn{1}{c}{ Schedule Properties } & \multicolumn{3}{c}{ Schedule Pairs } \\
& \multicolumn{1}{c}{ B } & \multicolumn{1}{c}{120} & \multicolumn{1}{c}{ C } \\
Center-key on-time & 120 & & 42 \\
SD Schedule: & & & \\
$\quad$ Times to reinforcement & 6,66 & 6,114 & 6 \\
Reinforcement/min. & 1.0 & 1.0 & 1.4 \\
V & .182 & .176 & .167 \\
HR Schedule: & & & \\
Times to reinforcement & 24,54 & 24,30 & $12,18,24$ \\
& 84,114 & 36,42 & 30,36 \\
Reinforcement/min. & 2.0 & 2.0 & 7.0 \\
V & .081 & .127 & .242 \\
Birds' preference & $\mathrm{SD}$ & $\mathrm{SD}$ & $\mathrm{HR}$
\end{tabular}

reinforcement; for pair $\mathrm{C}$, it was not. The number of free-choice trials required to bring about a reversal ranged from under 100 to over 400 . This variable will not be discussed further since it appears to depend upon many factors that were not specifically controlled in this experiment.

On each schedule, Ss acquired a characteristic pattern of responding corresponding to the sequence of fixed intervals. They would pause during the longer periods when reinforcement was unavailable; and respond at an increasing rate in anticipation of a reinforcement set-up time. This pattern caused the reinforcements to be delivered very close to their set-up times, and made the overall average rate of responding on the two schedules irrelevant for predicting preferential choice.

\section{Diseussion}

The results demonstrate that neither time to the first reinforcement nor overall reinforcement rate can alone be used to index schedule value. We propose a new index of value, $V$. The properties of $\mathrm{V}$ should be such that (a) for. VI schedules generated from arithmetic series, schedule value increases monotonically with reinforcement rate (Autor, 1960; Herrnstein, 1964a), and (b) it orders the present results. A $\mathrm{V}$ meeting these requirements is

$$
V=\sum_{i=1}^{n} \frac{\dot{p}_{i}}{t_{i}},
$$

where $\mathrm{n}$ is the total number of different delays of reinforcement after schedule presentation, $p_{i}$ is the prob- ability of delay interval, $t_{i}$, and $\mathrm{K}$ is a positive constant. Importantly, $t$ is the time between the choice response and reinforcement, not the time between successive reinforcements. $\mathrm{V}$ is identical to reinforcement rate for any set of interval schedules for which

$$
T_{i j}=a_{j} x_{i},
$$

where $T_{i j}$ is the ith inter-reinforcement interval in the $j$ th schedule in the set, $x_{i}$ is the ith interval in some fundamental schedule, e.g., the arithmetic series 1,2 , $3, \ldots n$, and $a_{j}$ is a constant used to generate the $T_{i j}$ from the $x_{i}, i=1,2,3, \ldots n$. Thus the VI schedules employed in Herrnstein's 1964a experiment more closely approximated such a set than the VI and FI schedules employed in his 1964b experiment, and so, as would be expected, the results of his 1964a experiment were much more consistent with an interpretation of $\mathrm{V}$ in terms of reinforcement rate. If the results of his 1964b experiment are analyzed in terms of $\mathrm{V}$, they fall into line with the results of his 1964 a experiment.

One implication of our results is that specification of VI, and probably also VR schedules in terms of reinforcement rate alone, is inadequate for comparisons among different schedules. It is recommended that both the inter-reinforcement intervals used, and the way in which they are programmed be reported. A small procedural matter, such as stopping the VI programmer during the interval between schedule presentations or not, since it effects the expected time to the first reinforcement, may be of major importance in the interpretation of the experimental results.

\section{Referenees}

AUTOR, S. M. The strength of conditioned reinforcers as a function of frequency and probability of reinforcement. Unpublished doctoral dissertation, Harvard University, 1960.

HERRNSTEIN, R. J. Secondary reinforcement and rate of primary reinforcement. J. exp. Anal. Behav., 1964(a), 7, 27-36.

HERRNSTEIN, R. J. Aperiodicity as a factor in choice. J. exp. Anal. Behav., 1964(b), 7, 179-182.

Note

1. This research was conducted in the Psychology Department at the University of Texas, and supported in part by Grant MH-07323-01 from the National Institute of Mental Health. We gratefully acknowledge the assistance of Jay Forrest and James Thomas Hall in collecting the data. The former participated as part of the Summer Science Program in Biology for High Ability Secondary School Students under the sponsorship of the National Science foundation. The latter served as a National Science Foundation Junior Research Participant under Grant GE-1894. 